\title{
Phospholipase D2 Ablation Ameliorates Alzheimer's Disease-Linked Synaptic Dysfunction and Cognitive Deficits
}

\author{
Tiago Gil Oliveira, ${ }^{1,2}$ Robin B. Chan, ${ }^{1,3,4}$ Huasong Tian, ${ }^{1}$ Mikael Laredo, ${ }^{1}$ Guanghou Shui,,${ }^{3,4}$ Agnieszka Staniszewski, ${ }^{1}$ \\ Hong Zhang, ${ }^{1}$ Lili Wang, ${ }^{1}$ Tae-Wan Kim, ${ }^{1}$ Karen E. Duff, ${ }^{1}$ Markus R. Wenk,,${ }^{3,4}$ Ottavio Arancio, ${ }^{1}$ and Gilbert Di Paolo ${ }^{1}$ \\ ${ }^{1}$ Department of Pathology and Cell Biology, Taub Institute for Research on Alzheimer's Disease and the Aging Brain, Columbia University Medical Center, \\ New York, New York 10032, '2Life and Health Science Research Institute, School of Health Sciences, University of Minho, 4710-057 Braga, Portugal, \\ ${ }^{3}$ Department of Biochemistry, The Yong Loo Lin School of Medicine, National University of Singapore, Singapore 117597, and ${ }^{4}$ Department of Biological \\ Sciences, The Yong Loo Lin School of Medicine, National University of Singapore, Singapore 117543
}

Growing evidence implicates aberrant lipid signaling in Alzheimer's disease (AD). While phospholipases A2 and C have been recently shown to mediate key actions of amyloid $\beta$-peptide $(\mathrm{A} \beta)$ through a dysregulation of arachidonic acid and phosphatidylinositol-4,5bisphosphate metabolism, respectively, the role of phospholipase D (PLD) has so far remained elusive. PLD produces phosphatidic acid (PA), a bioactive lipid involved in multiple aspects of cell physiology, including signaling and membrane trafficking processes. Here we show that oligomeric $A \beta$ enhances PLD activity in cultured neurons and that this stimulatory effect does not occur upon ablation of PLD2 via gene targeting. $A \beta$ fails to suppress long-term potentiation in PLD2-deficient hippocampal slices, suggesting that PLD2 is required for the synaptotoxic action of this peptide. In vivo PLD activity, as assessed by detection of phosphatidylethanol levels using mass spectrometry (MS) following ethanol injection, is also increased in the brain of a transgenic mouse model of AD (SwAPP). Furthermore, Pld2 ablation rescues memory deficits and confers synaptic protection in SwAPP mice despite a significant A $\beta$ load. MS-based lipid analysis of Pld2 mutant brains in the presence or absence of the SwAPP transgene unmasks striking crosstalks between different PA species. This lipid analysis shows an exquisite acyl chain specificity and plasticity in the perturbation of PA metabolism. Collectively, our results point to specific molecular species of PA as key modulators of AD pathogenesis and identify PLD2 as a novel potential target for therapeutics.

\section{Introduction}

Cerebral accumulation of amyloid $\beta(\mathrm{A} \beta)$ is believed to mediate many aspects of Alzheimer's disease (AD)-associated pathogenesis. $A \beta$ is produced by the sequential cleavage of the amyloid precursor protein (APP) by $\beta$ - and $\gamma$-secretases. While A $\beta 40$ is the predominant cleavage product, the longer peptide $A \beta 42$ is more cytotoxic and aggregate-prone (Small and Gandy, 2006; Haass and Selkoe, 2007; Vassar et al., 2009; De Strooper et al., 2010). Although AD brains typically harbor senile plaques that consist of insoluble aggregates of $A \beta$, different assemblies of $A \beta$, including fibrils as well as soluble dimers, trimers and dodecam-

\footnotetext{
Received June 27, 2010; revised Sept. 1, 2010; accepted Sept. 17, 2010.

This work was supported by National Institutes of Health Grants R01 NS056049 and P50 AG008702 (G.D.P.), and R01 NS049442 (0.A.), by the Singapore National Research Foundation under Competitive Research Programme Award No. 2007-04, the Biomedical Research Council of Singapore (R-183-000-211-305), and the National Medical Research Council (R-183-000-224-213) (M.R.W.); as well as from the Portuguese Foundation for Science and Technology SFRH/BD/33237/2007 and the Luso-American Development Foundation (T.G.0.). We thank Sung Ho Ryu and Pietro De Camilli for providing the PLD and synaptophysin antibodies, respectively; Min Suk Kang and Nuno Sousa for critical input; Elizabeta Micevska for technical help with the animals; Sergey Voronov for help with the pilot PLD assays; and Claudia Dall'Armi for the help with confocal microscopy and image analysis. We thank Diego Berman, Kimberly Robinson, Zachary Freyberg, and Scott Small for critical reading of this manuscript. We also thank Michael Frohman for the kind gift of the GFP-hPLD1 and GFP-mPLD2 constructs. Anti-A $\beta$ antibodies were a kind gift from Dr. Sonia Jung (Centocor).

Correspondence should be addressed to Dr. Gilbert Di Paolo, Columbia University Medical Center, Department of Pathology and Cell Biology, Taub Institute for Research on Alzheimer's Disease and the Aging Brain, 630 West 168th Street, P\&S 12-510, New York, NY 10032. E-mail: gil.dipaolo@columbia.edu.

DOI:10.1523/JNEUROSCI.3317-10.2010

Copyright $\odot 2010$ the authors $\quad 0270-6474 / 10 / 3016419-10 \$ 15.00 / 0$
}

ers, may differentially contribute to $\mathrm{AD}$ pathogenesis at various stages of this disorder (Lambert et al., 1998; Walsh et al., 2002; Haass and Selkoe, 2007). Importantly, elevation of soluble A $\beta$ oligomers strongly correlates with cognitive decline, consistent with the synaptotoxic properties exhibited by these peptides in various systems (Haass and Selkoe, 2007). For instance, $A \beta$ oligomers disrupt synaptic plasticity, the trafficking of glutamate receptors, dendritic spine dynamics and $\mathrm{Ca}^{2+}$ homeostasis (Demuro et al., 2005; Snyder et al., 2005; Hsieh et al., 2006; Haass and Selkoe, 2007; Shankar et al., 2007; Green and LaFerla, 2008). Importantly, recent work has suggested that $\mathrm{A} \beta$ oligomers may exert their effects upon binding to the cellular prion protein on the neuronal membranes (Laurén et al., 2009).

Mounting evidence indicates that $\mathrm{A} \beta$ perturbs the metabolism of intracellular signaling lipids and that this phenomenon contributes to the pathogenic actions of this peptide (Hartmann et al., 2007). In particular, work from our laboratory has shown that $\mathrm{A} \beta 42$ oligomers promote the hydrolysis of a major regulatory lipid phosphatidylinositol-4,5-bisphosphate $\left[\mathrm{PI}(4,5) \mathrm{P}_{2}\right]$ through a stimulation of the phospholipase C (PLC) pathway and that preventing $\mathrm{PI}(4,5) \mathrm{P}_{2}$ deficiency protects against the synapseimpairing actions of $\mathrm{A} \beta$ (Berman et al., 2008). Similarly, $\mathrm{A} \beta$ stimulates cytosolic phospholipase A2 (cPLA2), thereby enhancing the levels of arachidonic acid, and reduction of the relevant PLA2 isoform by genetic means confers protection against the peptide (Sanchez-Mejia et al., 2008). Collectively, these studies suggest that phospholipases may be primary mediators of $A \beta$ 's action. 
Phospholipase D (PLD), another family of phospholipases, has also been implicated in AD pathogenesis (Singh et al., 1995; Cai et al., 2006a; Brandenburg et al., 2008; Liu et al., 2009). PLD1 and PLD2, which are differentially localized in cells, hydrolyze phosphatidylcholine (PC) into choline and a bioactive lipid, phosphatidic acid (PA) (Freyberg et al., 2003; Jenkins and Frohman, 2005; Roth, 2008; Donaldson, 2009). This lipid regulates membrane dynamics and signaling processes through its intrinsic physical properties (i.e., "cone shape") and interaction with effector proteins (Jenkins and Frohman, 2005; Stace and Ktistakis, 2006; Haucke and Di Paolo, 2007; Roth, 2008; Raghu et al., 2009a). In the present study, we tested the involvement of PLD2 in $\mathrm{AD}$ pathogenesis and more specifically, in the synaptotoxic action of $\mathrm{A} \beta$ oligomers. We reasoned that PLD2 was likely to mediate the previously reported increase in total PLD activity induced by $\mathrm{A} \beta$, based on the predominant localization of this isozyme at the cell surface (Du et al., 2004), a major site of action for $\mathrm{A} \beta$. We show that ablating PLD2 through genetic means blocks the synaptotoxic action of $A \beta 42$ oligomers and rescues memory deficits in a transgenic model of AD independently of brain $\mathrm{A} \beta$ levels.

\section{Materials and Methods}

Cell culture. PC12 cells were maintained in DMEM with sodium pyruvate (Invitrogen) supplemented with 5\% fetal bovine serum, 10\% horse serum, glutamine $(4 \mathrm{~mm})$, penicillin $(200 \mathrm{U} / \mathrm{ml})$, streptomycin $(200 \mu \mathrm{g} /$ $\mathrm{ml}$ ); cells were maintained at $37^{\circ} \mathrm{C}$ in $5 \% \mathrm{CO}_{2}$. Twenty-four hours before transfection, PC12 cells were plated (at 50\% confluence) on coverslips precoated with polylysine $(20 \mu \mathrm{g} / \mathrm{ml})$ for $1 \mathrm{~h}$ at $37^{\circ} \mathrm{C}$. Transfections of GFP-mouse PLD2 construct (kind gift from Michael Frohman, SUNY, Stony Brook, NY), which was previously described (Du et al., 2004), were obtained using Lipofectamine 2000 (Invitrogen). Primary cultures from cortical neurons were generated from newborn wild-type mice. Briefly, cortices were dissected out, trypsinized for $30 \mathrm{~min}$, and then cortical cells dissociated with a Pasteur pipette and plated on poly-ornithinecoated $10 \mathrm{~mm}$ dishes at a density of $25,000 \mathrm{cells} / \mathrm{cm}^{2}$ in Neurobasal-A medium containing $1 \mathrm{~mm}$ kynurenic acid to reduce enhanced synaptic transmission due to the high density of the cultures. Treatments with oA $\beta 42$ were typically performed after 15 days in vitro, with $200 \mathrm{~nm}$ concentration and with time duration of $4 \mathrm{~h}$ for primary neuronal cultures and 5, 30 and $60 \mathrm{~min}$ in PC12 cells. Ionomycin was used with $2 \mu \mathrm{M}$ concentration for $30 \mathrm{~min}$.

Peptide preparation. A $\beta$ oligomers were prepared as described previously (Dahlgren et al., 2002). Synthetic A $\beta$ (1-42) was purchased from American Peptide and stored at $-20^{\circ} \mathrm{C}$. The vial containing the peptide was allowed to equilibrate to room temperature for at least $30 \mathrm{~min}$ before resuspension. In a fume hood the peptide was diluted to $1 \mathrm{~mm}$ in 1,1,1,3,3,3-hexafluoro-2-propanol (HFIP) by pipette mixing and immediately aliquoted in polypropylene microcentrifuge tubes. The solution was vortexed briefly and allowed to evaporate in the fume hood for $2 \mathrm{~h}$. The resulting peptide films were dried in a Speed Vac for $10 \mathrm{~min}$ at $800 \times$ $g$ and stored at $-20^{\circ} \mathrm{C}$. Before use, the peptide film was resuspended to 1 $\mathrm{mm}$ in DMSO by pipette mixing followed by bath sonication for $10 \mathrm{~min}$. The solution was aliquoted in polypropylene microcentrifuge tubes and stored at $-20^{\circ} \mathrm{C}$. The peptide was used within 2 weeks of dilution in DMSO. Oligomeric forming conditions: the $1 \mathrm{~mm}$ DMSO solution was diluted to $100 \mu \mathrm{M}$ in cold PBS, vortexed for $30 \mathrm{~s}$, and incubated overnight at $4^{\circ} \mathrm{C}$ (minimum incubation of $12 \mathrm{~h}$ ). Immediately before use, the $\mathrm{A} \beta$ PBS solution was further diluted in culture media to the required final concentration and vortexed briefly. This preparation contains a mixture of monomers, trimers and tetramers as well as traces of dimers and high molecular weight oligomers, as shown previously (Berman et al., 2008).

Mouse strains and breeding strategy. The genetic background of the Pld2 mice is mixed (C57BL/6-129svj). Pld2 ${ }^{-1-}$ females were crossed with Tg2576 males (Taconic; mixed background C57BL/6-SJL/N), which express human APP carrying the double mutation K670N and M671L found in a Swedish family with early onset of Alzheimer's disease, under the regulation of the hamster prion protein promoter (Hsiao et al., 1996). From the $\mathrm{F}_{1}$ hybrid generation we used as breeders $P l d 2^{+/-} /$no tg females and $P l d 2^{+/-} /$SwAPP males. For all our animal studies we used littermate mice (or in some cases, mice sharing at least one parent) derived from the $\mathrm{F}_{2}$ generation. The survival rate of adult mice was $>90 \%$ for all genotypes within the first 12 months of age (and thus the impact of Pld2 deletion on the survival of SwAPP mice was not investigated further).

ELISA analysis. Brains were homogenized in 10 volumes of $50 \mathrm{~mm}$ Tris- $\mathrm{HCl}$ buffer, $\mathrm{pH}$ 7.6, containing $250 \mathrm{~mm}$ sucrose and protease inhibitor cocktail (Sigma). Soluble and total A $\beta$ were extracted in $0.4 \%$ diethylamine (DEA) and $70 \%$ formic acid, respectively, as previously described (Schmidt et al., 2005). Levels of full-length $A \beta$ 1-40 and 1-42 were quantified using antibodies donated by Centocor according to previously published ELISA procedures (Schmidt et al., 2005). Murine A $\beta$ was measured according to a previously published procedure (Burns et al., 2003).

Western blot analysis. The DEA fraction of brain extracts from Pld2/ SwAPP mutant mice was immunoblotted using a rabbit polyclonal antibody to the COOH terminus of PLD (kind gift from Dr. Sung Ho Ryu, Pohang University of Science and Technology, Pohang, South Korea), rabbit polyclonal antibody to PLD1 (Cell Signaling Technology), mouse monoclonal antibody to APP (6E10, Covance), mouse monoclonal antibody to PSD95 (6G6-1C9, Abcam), rabbit polyclonal synaptophysin (G95, kind gift from Dr. Pietro De Camilli, Yale University, New Haven, CT), and a mouse monoclonal antibody to $\alpha$-tubulin (B-5-1-2, Sigma). Quantification was performed using ImageJ software.

PLD activity in neuronal cultures. Ten-day-old neurons were incubated with $\left[{ }^{3} \mathrm{H}\right]$ palmitic acid $(2 \mu \mathrm{Ci} / \mathrm{ml})$ for $\sim 5 \mathrm{~d}$ to label cellular phospholipids. Following treatments with vehicle or oA $\beta 42$, neurons were incubated in the presence of $0.3 \%$ butanol for $30 \mathrm{~min}$, which leads to the production and accumulation of $\left[{ }^{3} \mathrm{H}\right]$ phosphatidylbutanol via a PLDspecific transphosphatidylation reaction. Radiolabeled lipids, including phosphatidylbutanol, were isolated by solvent extraction and separated by thin-layer chromatography. The total amount of $\left[{ }^{3} \mathrm{H}\right]$ phosphatidylbutanol is expressed as a percentage of total ${ }^{3} \mathrm{H}$-labeled lipids (Morris et al., 1997).

Confocal microscopy: analysis of GFP-PLD2 internalization. Twentyfour hours after transfection with a plasmid encoding GFP-PLD2, PC12 cells were incubated with vehicle or $200 \mathrm{~nm} \mathrm{oA} \beta 42$ for 5, 30 and $60 \mathrm{~min}$. Other treatments included $2 \mu \mathrm{M}$ ionomycin (Sigma-Aldrich), $2 \mathrm{~mm}$ EGTA (Sigma-Aldrich), $250 \mathrm{~nm}$ U-73122 (Calbiochem), and $20 \mu \mathrm{M}$ AACOCF3 (Calbiochem) for $30 \mathrm{~min}$, as indicated in the figure legend. Cells were then washed in phosphate buffer and fixed with $4 \%$ paraformaldehyde. Confocal $z$-stack images $(0.5 \mu \mathrm{m})$ of PC12 were obtained using a Nikon EZ-C1.2.30 confocal microscope and an oil-immersion objective $(100 \times)$. Quantification of GFP intensity was calculated using the ImageJ software: for each cell in a given image, a line intensity profile across the cell was obtained. The relative decrease in plasma membrane localization was calculated as the ratio between the plasma membrane fluorescence intensity and the average cytosolic fluorescence intensity, as previously described (Berman et al., 2008).

Electrophysiology. Transverse hippocampal slices $(400 \mu \mathrm{m})$ were cut with a tissue chopper (EMS, PA) and maintained in an interface chamber at $29^{\circ} \mathrm{C}$ for $90 \mathrm{~min}$ before recording, as previously reported (Puzzo et al., 2005). CA1 field EPSPs (fEPSPs) were recorded by placing both the stimulating and the recording electrodes in CAl stratum radiatum. Basal synaptic transmission (BST) was evaluated either by plotting the stimulus voltages $(\mathrm{V})$ against slopes of fEPSP, or by plotting the peak amplitude of the fiber volley against the slope of the fEPSP, to generate input-output relations. During baseline recordings, responses were evoked at an intensity of $\sim 35 \%$ of the maximum evoked response LTP was induced using a $\theta$-burst stimulation ( 4 pulses at $100 \mathrm{~Hz}$, with bursts repeated at $5 \mathrm{~Hz}$ and each tetanus including three 10-burst trains separated by $15 \mathrm{~s}$ ). oA $\beta 42$ was applied for $20 \mathrm{~min}$ before the $\theta$-burst.

Fear conditioning. The capacity of the mice for contextual and cued memory was tested as before (Paylor et al., 1994; LeDoux, 2000; Gong et al., 2006), with slight modifications. Briefly, mice were first exposed for 2 min to the context before the onset of a tone (a $30 \mathrm{~s}, 85 \mathrm{~dB}$ sound at 2800 
$\mathrm{Hz}$ ) serving as a conditioning stimulus (CS). In the last $2 \mathrm{~s}$ of the CS, mice received a $2 \mathrm{~s}, 0.50 \mathrm{~mA}$ foot shock [unconditioned stimulus (US)] through the bars of the floor. Freezing, which is defined as a speciesspecific defensive reaction characterized by lack of movement, associated with crouching posture was measured right after the end of the CS/US for $30 \mathrm{~s}$ using the Freezeview software (MED Associates Inc.). The contextual memory test was performed $24 \mathrm{~h}$ later, by reexposure of the mice to the same context and by measuring the proportion of freezing time during 5 $\mathrm{min}$. To evaluate cued fear learning, $24 \mathrm{~h}$ after contextual testing, mice were placed into a novel context for $2 \mathrm{~min}$ (pre-CS test), followed by an exposure to the CS for $3 \mathrm{~min}$ (CS test), during which freezing was measured. No differences were found between the six genotypes in this control test (data not shown). For all the fear conditioning experiments, the conditioning chamber is located inside a sound-attenuating box $(72 \mathrm{~cm} \times 51 \mathrm{~cm} \times 48$ $\mathrm{cm})$. A clear Plexiglas window $(2 \mathrm{~cm} \times 12 \mathrm{~cm} \times 20 \mathrm{~cm})$ allows the researcher to digitally record the mouse performance with a camera placed on a tripod and connected to Freezeframe software (MED Associates Inc.).

Radial arm water maze. The test was performed as before (Trinchese et al., 2008) in a white tank filled with milky water, and containing stainless steel walls positioned to produce six arms, radiating from a central area. Spatial cues were presented on the walls of the testing room. At the end of one of the arms there was a clear $10 \mathrm{~cm}$ Plexiglas submerged $(1.5 \mathrm{~cm})$ platform, which remained in the same location for every trial in $1 \mathrm{~d}$, but was moved randomly each day. On each trial, the mouse started the task from a different randomly chosen arm. The mouse could not use longterm memory of the location of the platform on previous days, but had to rely on the short-term memory of its location in the same day based on spatial cues. Each trial lasted $1 \mathrm{~min}$ and errors are counted each time the mouse entered the wrong arm with four paws, or needed $>20$ s to reach the platform. After each error, the mouse was gently pulled back to the start arm for that trial. After four consecutive trials, it was placed in its home cage for $30 \mathrm{~min}$, and then administered a retention trial. Testing was considered complete when wild-type mice reached asymptomatic performance (below one error on trials 4 and $5 ; 10$ training days). Scores for each mouse on the last $3 \mathrm{~d}$ of testing were averaged and used for statistical analysis. All behavioral experiments were done blind to the genotype. Visible-platform tests to detect visual, motor or motivational impairments were performed in the same pool, but without arms and with the platform marked with a black flag, once the radial arm water maze (RAWM) study was completed. Platform location was varied randomly to eliminate any contribution of external spatial cues. Four trials per day were given over $2 \mathrm{~d}$. Each animal was allowed to swim for $1 \mathrm{~min}$ from a random location. Once the mouse reached the platform (or with help if it did not reach it on its own), it was allowed to rest there for $30 \mathrm{~s}$. Failures to reach the platform are scored as $60 \mathrm{~s}$. Data were recorded using a ceiling-mounted camera and analyzed with an HVS-2020 video tracking system.

In vivo PLD activity. Nontransgenic and SwAPP mice were injected intraperitoneally with $3 \mathrm{~g} / \mathrm{kg}$ ethanol. Mice were killed $1 \mathrm{~h}$ postinjection. Forebrains were then removed from the mice and levels of phosphatidylethanol (PEtOH) produced via a $\mathrm{PLD}$-specific transphosphatidylation reaction were measured in lipid extracts via mass spectrometry, as described below.

Mass spectrometry. Lipid extracts were prepared from mice forebrain using a modified Bligh and Dyer method and analyzed by liquid chromatography-mass spectrometry (LC-MS). Polar glycerophospholipids and sphingolipids were separated via a Luna silica column $(3 \mu \mathrm{m}$, $2 \mathrm{~mm} \times 150 \mathrm{~mm}$; Phenomenex) with a solvent gradient of $100 \%$ chloroform/methanol/water/ammonia solution (90:9.5:0.5:0.32, v/v) changing to $100 \%$ chloroform/methanol/water/ammonia solution (50:48:2: 0.32 , v/v) over $40 \mathrm{~min}$ (Pettitt et al., 2001). Lipid species were measured using a triple quadrupole instrument ABI 4000 Q-Trap (Applied Biosystems) operated in a multiple-reaction monitoring (MRM) mode. Both $\mathrm{PA}$ and $\mathrm{PEtOH}$ species were measured using MRM transition pair of parent ion $\mathrm{m} / \mathrm{z}$ to fatty acyl chain $\mathrm{m} / \mathrm{z}$ using instrument settings as described previously (Chan et al., 2008; Fei et al., 2008). PA levels were quantified by referencing to known amounts of spiked internal standard diC17-PA (Avanti Polar Lipids). PEtOH levels were referenced to spiked internal standard diC16-PEtOH (Avanti Polar Lipids), which was added in excess of endogenous levels of this species.
Statistics. Statistical analysis was performed using two-tailed equal variance and Student's $t$ test, unless indicated otherwise. All the experiments were performed in blind to the genotypes.

\section{Results}

Reduction in PLD2 levels blocks A $\beta$-induced PLD activation

To begin to address the role of PLD in $\mathrm{A} \beta$ pathogenesis and to determine which of the two isoforms may be stimulated by $\mathrm{A} \beta$, we tested whether oligomeric $A \beta$ signaling alters the subcellular localization of either PLD1 or PLD2. Indeed, previous work from others has indicated that stimulation of these enzymes enhances their transport to and from the cell surface (Du et al., 2003; Laulagnier et al., 2004). Pheochromocytoma cell line PC12 was transfected with constructs encoding either GFP-PLD1 or GFP-PLD2, whose localization was analyzed after an acute treatment with 200 nM A $\beta 42$ oligomers (oA $\beta 42$ ). As expected (Du et al., 2004), in the absence of treatment or in the presence of vehicle, the fluorescence of GFP-PLD2 was concentrated at the plasma membrane (Fig. $1 A, B$ ) while the fluorescence of GFP-PLD1 was more intracellular (data not shown), likely reflecting the predominant localization of this isoform in the Golgi complex as well as in secretory granules and endosomes (Jenkins and Frohman, 2005; Roth, 2008; Bader and Vitale, 2009). Incubation of PC12 cells with $200 \mathrm{nM} \mathrm{oA} \beta 42$ for 5, 30, and $60 \mathrm{~min}$ did not produce an obvious effect in localization pattern of GFP-PLD1 (data not shown). On the other hand, while incubation of PC12 cells with oA $\beta 42$ did not significantly affect the localization of GFP-PLD2 after $5 \mathrm{~min}$, it triggered a partial internalization of this probe after 30 and 60 min (Fig. $1 A, B$ ). This effect was mimicked by a treatment with $2 \mu \mathrm{M}$ ionomycin, a $\mathrm{Ca}^{2+}$ ionophore and a known PLD2 activator (Kim et al., 1999), and it was blocked by preincubation with $2 \mathrm{~mm}$ EGTA, an extracellular $\mathrm{Ca}^{2+}$ chelator, indicating that the oA $\beta 42$ effect on PLD2 is $\mathrm{Ca}^{2+}$-dependent (Fig. 1C). Based on previous work showing an activation of both the PLC and CPLA2 pathways downstream of A $\beta$ (Kanfer et al., 1998; Kriem et al., 2005; Berman et al., 2008; Sanchez-Mejia et al., 2008; Oliveira and Di Paolo, 2010), we tested whether $\mathrm{A} \beta$-induced GFP-PLD2 relocalization was dependent upon PLC or cPLA2 using pharmacological inhibitors (i.e., U-73122 and AACOCF3, respectively). While the PLC inhibitor had no effect on the localization of GFP-PLD2, the cPLA2 inhibitor blocked the relocalization of GFP-PLD2 in response to oA $\beta 42$, suggesting that this phenomenon is independent or upstream of PLC but likely downstream of cPLA2 (Fig. 1D).

To test whether PLD2 mediates cytotoxic actions of $A \beta$ oligomers, we developed a mouse genetic model lacking PLD2 (supplemental Fig. 1A,B, available at www.jneurosci.org as supplemental material). Mutant mice do not exhibit any overt phenotype. Western blot analysis using specific antibodies showed that the PLD2 immunoreactivity is absent and approximately decreased by $50 \%$ in adult brain tissue derived from Pld $2^{-1-}$ and Pld $2^{+1-}$ mice, respectively (see Fig. $6 A$ ). To confirm that PLD2 ablation produces a significant decrease in total PLD activity in brain tissue, we developed an in vivo PLD activity assay relying on the intraperitoneal injection of adult mice with ethanol and measurement of phosphatidylethanol (PEtOH) (i.e., the product of PLD) $1 \mathrm{~h}$ postinjection in the adult brain of $\mathrm{Pld} 2^{+/+}$and $\mathrm{Pld} 2^{-1-}$ mice using liquid chromatography-mass spectrometry (LC-MS) (Pettitt et al., 2001; Chan et al., 2008). We found a $40 \%$ decrease of PEtOH levels in the brain of $\mathrm{Pld} 2^{-1-}$ mice (supplemental Fig. 1C, available at www.jneurosci.org as supplemental material), thus indicating that PLD2 contributes a 
significant fraction of total PLD activity in the adult brain (with the remainder likely accounted for by PLD1).

To begin to determine the role of PLD2 in the $A \beta$ signaling pathway, we tested whether the oligomeric peptide preparation used in this study (oA $\beta 42)$ enhances total PLD activity in primary cortical neurons. Indeed, previous work from others had shown that treatment of neuronal cell lines with micromolar concentrations of A $325-35$ increases PLD activity (Singh et al., 1995, 1998; Kanfer et al., 1998; Oliveira and Di Paolo, 2010). Here, total PLD activity was analyzed in cultured neurons following metabolic labeling with $\left[{ }^{3} \mathrm{H}\right]$ myristic acid in the presence of low concentrations of 1 -butanol and quantification of PLD's transphosphatidylation product, phosphatidylbutanol (Fig. 2). In the absence of $A \beta$ oligomer treatment, basal PLD activity was significantly decreased by $30 \pm 11 \%$ and $74 \pm$ $13 \%$ in Pld $2^{+/-}$and Pld $2^{-1-}$ neurons, respectively. Remarkably, oA $\beta 42$ application led to a $\sim 2$-fold increase in total PLD activity in Pld2 $2^{+/+}$neurons (Fig. 2), an effect comparable to that obtained with 2 $\mu \mathrm{M}$ ionomycin (i.e., a $92 \pm 11 \%$ increase, $n=6, p<0.001)$. However, oA $\beta 42$ failed to increase this activity in Pld $2^{+/-}$as well as in Pld2 $2^{-1-}$ neurons (Fig. 2), indicating that the PLD2 isoform is involved in the $\mathrm{A} \beta$ signaling cascade.

\section{Ablation of PLD2 blocks the suppressive effect of $A \boldsymbol{\beta}$ oligomers on LTP}

If the activation of PLD is necessary for oA $\beta 42$-induced synaptic dysfunction, the ablation of Pld2 may confer a resistance against the peptide with respect to neurophysiology. To test this, the effect of oA $\beta 42$ on synaptic transmission was assessed in adult hippocampal slices from $\mathrm{Pld} 2^{+/+}$and $\mathrm{Pld} 2^{-/-}$mice, where recordings were performed in the CA1 hippocampal region after stimulation of the Schaffer collateral pathway. First, basal neurotransmission (input-output) was investigated and found to be normal in Pld $2^{-l-}$ slices in the absence of the peptide (supplemental Fig. 2, available at www.jneurosci.org as supplemental material). Next, long-term potentiation (LTP) was induced by a tetanic stimulation after exposing slices from the two genotypes to $200 \mathrm{nM}$ oA $\beta 42$ or vehicle for $20 \mathrm{~min}$. LTP in Pld $2^{+/+}$slices was comparable to that obtained in $P l d 2^{-1-}$ slices in the presence of vehicle (Fig. 3 ). However, while oA $\beta 42$ partially impaired LTP in Pld $2^{+/+}$control slices, as reported before (Lambert et al., 1998; Vitolo et al., 2002; Haass and Selkoe, 2007), the effect of this crude oligomer preparation on LTP was strongly suppressed in $\mathrm{Pld} 2^{-/-}$ slices (Fig. 3), suggesting that the ablation of PLD2 prevents $A \beta 42$ oligomers from exerting their synaptotoxicity.

\section{PLD activity is increased in the brain of a transgenic model of $\mathrm{AD}$}

To understand the in vivo relevance of the PLD pathway in an AD model, we subjected the transgenic line Tg2576, which expresses
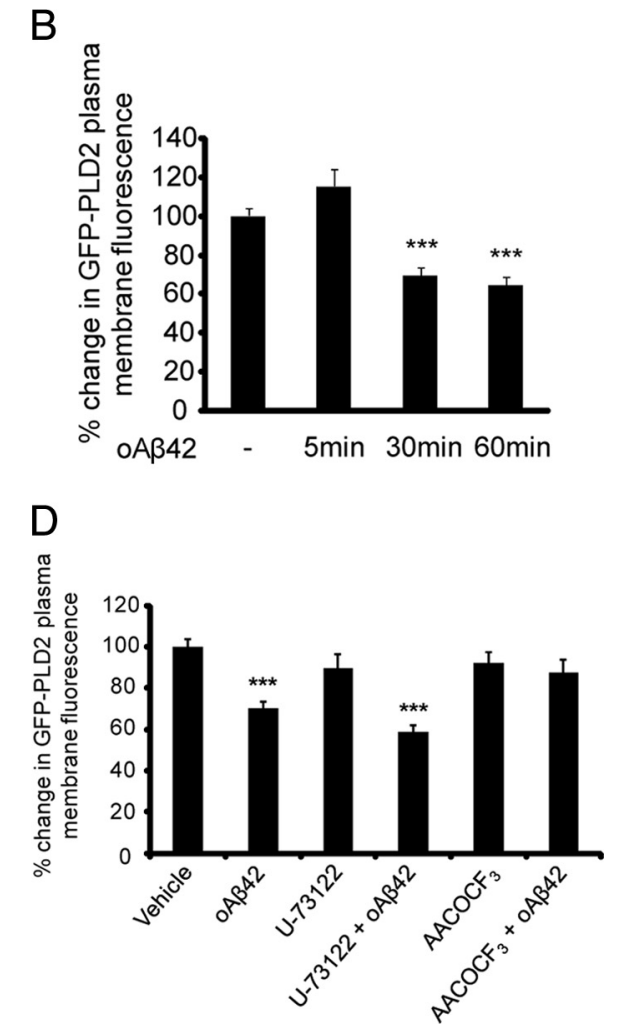

Figure 1. $\quad \mathrm{PLD} 2$ lies in the $A \beta$ signaling pathway. $\boldsymbol{A}, \mathrm{PC12}$ cells were transfected with a plasmid expressing GFP-PLD2. Representative examples show internalization of GFP-PLD2 after treatments with $200 \mathrm{~nm} 0 \mathrm{~A} \beta 42$. Pictures show the fluorescence of uantified as the $\mathrm{PM} /$ cytosol ratio ( $0 \mathrm{~min}, n=31 ; 5 \mathrm{~min}, n=29 ; 30 \mathrm{~min}, n=32 ; 60 \mathrm{~min}, n=30$ ). C, Effect of 30 min treatments 列 (n) presence or absence of $200 \mathrm{~nm} 0 A \beta 42$. The number of cells analyzed was as follows: vehicle $(n=$ 97), oA $\beta 42(n=81), \mathrm{U} 73122(n=41), \mathrm{U} 73122+0 \mathrm{~A} \beta 42(n=42), \mathrm{AACOCF} 3(n=50), \mathrm{AACOCF} 3+0 \mathrm{~A} \beta 42(n=45)$. For $\boldsymbol{B}-\boldsymbol{D}$, values denote means \pm SEM. $\left.{ }^{*} p<0.05,{ }^{* * *} p<0.001\right)$.

the Swedish APP (SwAPP) mutant (Hsiao et al., 1996) to acute ethanol injections, so as to conduct in vivo measurements of PLD activity as described above. We used aged (i.e., 14-month-old) mice for these studies, because $A \beta$ levels are known to increase in an age-dependent fashion in the forebrain of these animals, thus leading to well established cognitive deficits (Hsiao et al., 1996). We found that total PEtOH levels are increased by $25 \pm 11 \%(n=6, p<$ 0.05 ) in the forebrain of SwAPP mice relative to controls, indicating an overall enhancement of PLD activity in mutant animals. More specifically, there was a significant increase in a subset of molecular species of PEtOH (32:1, 34:2, 34:1 and 34:1) and an overall trend for an increase in the other $\mathrm{PEtOH}$ species analyzed, with the exception of 38:2 (Fig. 4; see also supplemental Table 1, available at www. jneurosci.org as supplemental material for absolute levels of PEtOH species). This is to our knowledge the first in vivo evidence in support of a dysfunction of the PLD pathway in an AD mouse model.

\section{Reducing PLD2 levels ameliorates the memory deficits of a transgenic model of AD}

Next, the impact of Pld2 ablation on learning behavior was assessed in the SwAPP mice. To this goal, mice of the three Pld2 genotypes $(+/+,+/-,-/-)$ in the transgenic (SwAPP) or nontransgenic (no SwAPP) background were subjected to the contextual fear conditioning paradigm, which assesses a form of emotional learning that requires normal amygdala and hip- 


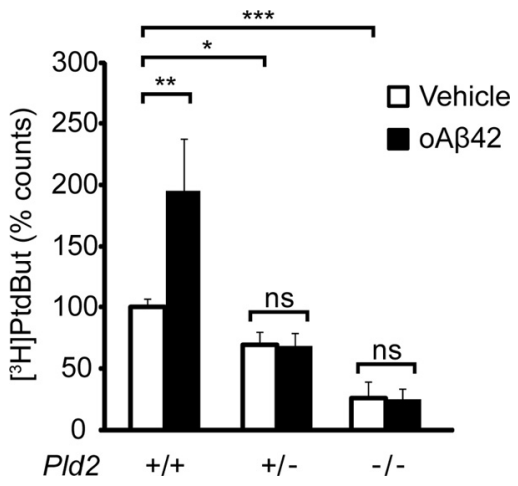

Figure 2. Ablation of PLD2 reduces basal PLD activity and abolishes the stimulatory effect of $A \beta$ oligomers on PLD activity in cultured neurons. Primary cortical cultures were labeled with $\left[{ }^{3} \mathrm{H}\right]$ myristic acid at day 12 , treatments were performed at day 15 , lipids were subsequently extracted and the ratio $\left[{ }^{3} \mathrm{H}\right]$ phosphatidylbutanol counts/total counts was used as a measure of PLD activity. Four-hour treatments with vehicle or $0 \mathrm{~A} \beta 42200 \mathrm{~nm}$ were performed before PLD activity measurement in PId2 ${ }^{+/+}$( $n=19$ and 12 for vehicle and $0 A \beta 42$ treatment, respectively), PId $2^{+/-}(n=7)$, and PId $2^{-/-}(n=5$ and 7 , respectively). Values denote means \pm SEM. ns, Nonsignificant. ${ }^{*} p<0.05,{ }^{* *} p<0.01,{ }^{* * *} p<0.001$.

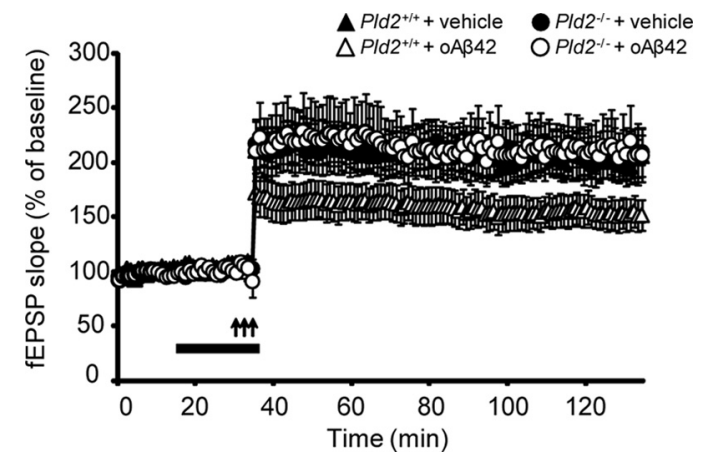

Figure 3. LTP is unaffected by $0 A \beta 42$ in $P I d 2^{-/-}$hippocampal slices. There was no difference in LTP between PId $2^{+/+}$slices and PId $2^{-1-}$ slices in the presence of vehicle $\left(F_{(1,17)}=\right.$ $0.01, p=0.9473)$. Although PId2 ${ }^{+/+}$slices showed a reduction of LTP following bath application of $200 \mathrm{~nm} 0 \mathrm{~A} \beta 42\left(F_{(1,16)}=5.19, p=0.0367\right.$, relative to vehicle), LTP was not reduced by the peptide in PId2 ${ }^{-l-}$ slices $\left(F_{(1,14)}=0.01, p=0.9185\right.$, relative to vehicle). fEPSP, CA1 field-EPSP. The bar represents the time of bath application of $0 A \beta 42$. The three arrows represent the $\theta$-burst stimulation used to induce potentiation. Animals were $\sim 3$ months old. Values denote means \pm SEM $(n=8-9)$. Note that the vehicle traces for both PId2 genotypes (i.e., black filled triangles and circles) are largely overlapping.

pocampus function. In this task, an innocuous conditioned stimulus (tone) elicits fear response after being associatively paired with an aversive unconditioned stimulus (footshock). The fear response is measured by the frequency of freezing behavior, which is defined as a stereotyped motionless crouching posture. For these experiments, 5- to 6-month-old mice were used, because our preliminary studies had shown that SwAPP mice, in this age category, exhibit learning deficits, which are not associated with a significant neuritic plaque burden and thus likely reflect the effects of soluble $\mathrm{A} \beta$ assemblies. Mice from all six genotypes did not show any major differences in the baseline levels (pretesting). As expected, the SwAPP mice, unlike nontransgenic mice, exhibited little contextual fear response $24 \mathrm{~h}$ after the pretest, thus denoting an impairment in contextual learning in the presence of a normal copy number for Pld2. However, transgenic mice lacking one (SwAPP/Pld2 ${ }^{+/-}$) or two (SwAPP/Pld $2^{-l-}$ ) copies of Pld2 performed better than the SwAPP/Pld $2^{+/+}$mice (Fig. $5 A$ ), suggesting that genetic ablation of $\mathrm{Pld} 2$ is protective.

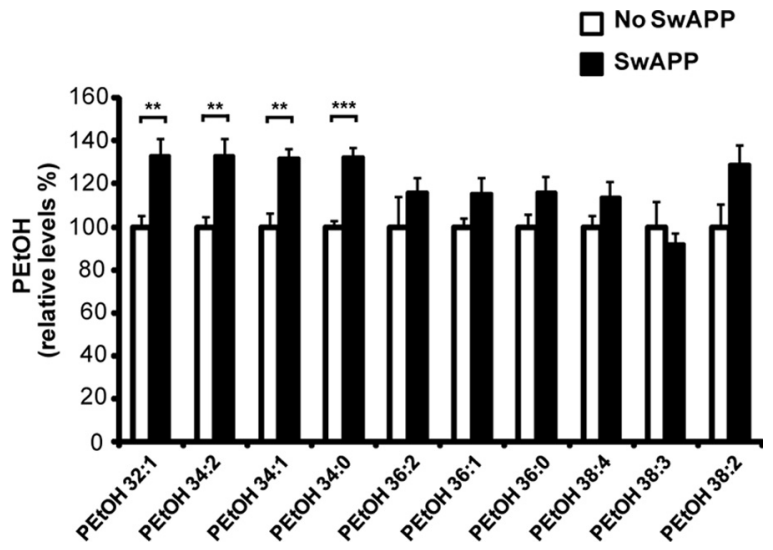

Figure 4. PLD activity is enhanced in the forebrain of aged SwAPP mice. Mice, with and without SwAPP transgene, were injected with $3 \mathrm{~g} / \mathrm{kg}$ ethanol, and their forebrain lipids were extracted and subjected to LC-MS analysis. The production and accumulation of PEtOH was used as a reporter of in vivo $\mathrm{PLD}$ activity. Relative individual $\mathrm{PEt} O \mathrm{OH}$ species were measured in mutant mice compared with control mice. The nomenclature for fatty acid composition of phospholipids is denoted as total chain length/number of unsaturated bonds. Values denote mean $\pm \operatorname{SEM}(n=6)$. ${ }^{* *} p<$ $0.01,{ }^{* * *} p<0.001$. Absolute amounts of the various molecular species of $\mathrm{PEtOH}$ are presented in supplemental Table 1, available at www.jneurosci.org as supplemental material.

Next, mice were subjected to a second learning task, the RAWM paradigm, which assesses spatial working memory. In this test, mice have to find a hidden platform, at the end of one of six arms, remaining in the same location for every trial in $1 \mathrm{~d}$, but moved to another location from day to day. For each trial, mice start the task from a different randomly chosen arm. After four consecutive trials mice are returned to the cage and submitted to a fifth trial (retention test) $30 \mathrm{~min}$ later. While the SwAPP/ $\mathrm{Pld} 2^{+/+}$mice showed impaired memory after $10 \mathrm{~d}$ of training (cf. Trinchese et al., 2008), mice lacking one (SwAPP/Pld $2^{+/-}$) or two (SwAPP/Pld $2^{-/-}$) copies of Pld2 perform similarly as animals that do not express SwAPP (Fig. 5B), indicating that, as in the fear conditioning test, reduction of PLD2 was protective for the deficits induced by overexpression of the transgene and increased $\mathrm{A} \beta$ load. The six groups of mice analyzed showed no overall major differences in the escape latency in the visible platform task, as well as in the swimming speed (supplemental Fig. 3, available at www.jneurosci.org as supplemental material) indicating that differential vision, locomotor activity or motivation did not influence the outcome of the RAWM testing.

\section{Reducing PLD2 levels maintains synaptic protein levels in a} transgenic model of $\mathrm{AD}$

Since a reduction or ablation of PLD2 confers protection against the deleterious effects of oA $\beta 42$ on LTP (Fig. 3) and of SwAPP overexpression on learning and memory (Fig. 5), a likely possibility is that lack of PLD2 exerts a synapse-protecting effect. To test this, levels of presynaptic and postsynaptic proteins which are known to be affected by A $\beta$ elevation and SwAPP overexpression (Almeida et al., 2005) were investigated. We found that ablation of either one or two copies of PLD2 does not affect the forebrain levels of synaptophysin (presynaptic marker) and PSD95 (postsynaptic marker) in the absence of SwAPP transgene. However, while expression of the SwAPP transgene leads to a significant decrease in the levels of PSD95 and, to a lesser extent, synaptophysin, PLD2 ablation restored the levels of these two synaptic proteins to normal levels, with partial phenotypes observed for SwAPP/Pld2 ${ }^{+/-}$mice (Fig. 6). These biochemical data are in agreement with the notion that PLD2 ablation may confer 
synaptic protection in the context of the SwAPP background. Because synaptic protein levels are not altered by the Pld2 genotype (Fig. 6) and that the electrophysiology analysis shows a normal input-output relationship in mutant hippocampi in the absence of SwAPP transgene (supplemental Fig. 2, available at www.jneurosci.org as supplemental material), we speculate that the protective mechanism likely does not involve a gross increase in the number of functional synapses in the mutant.

\section{Effect of the APP transgene expression and PLD2 ablation on brain \\ PA metabolism}

To gain insight into the molecular basis underlying AD pathogenesis as well as the protection conferred by PLD2 ablation, we focused our analysis on PA, the product of PLD. A mass spectrometry analysis of mutant animals was performed covering different species of PA. Total forebrain lipids were extracted from 11 - to 12 month-old Pld $2^{+/+}$and Pld $2^{-1-}$ mice in the presence or absence of the SwAPP transgene and analyzed using LC-MS. Three classes of potential lipid alterations were investigated: (1) changes produced by the ablation of PLD2; (2) changes occurring in response to the overexpression of SwAPP; and (3) changes reflecting interactions between the SwAPP transgene and the Pld 2 genotypes. Results are expressed either in the form of molar percentages in a table (supplemental Table 2, available at www. jneurosci.org as supplemental material) or in the form of bar graph relative to control brains (Pld $2^{+/+}$, no SwAPP) (Fig. 7).

The data show that ablation of PLD2 significantly decreases the levels of two molecular species of PA based on the different fatty acyl composition (see legend), namely, PA 32:1 ( 50\%) and $38: 4(\sim 40 \%)$, while a trend for a decrease ( $\sim 20 \%)$ was observed for two other species, PA 34:1 and 34:0 (Fig. 4B; supplemental Table 2, available at www.jneurosci.org as supplemental material). Surprisingly, the PA 32:0 and 38:2 species were upregulated (by $25 \%$ and $\sim 30 \%$, respectively), suggesting the occurrence of compensatory mechanisms in Pld2 knock-out brains. Indeed, the total amount of PA (i.e., sum of all species measured) was overall unaffected by the Pld2 genotype, thus denoting a tremendous plasticity in the metabolism of PA. In agreement with this report's findings showing increased PLD activity in response to $\mathrm{A} \beta$ application in neuronal cultures (Fig. 2), SwAPP overexpression leads to a selective $35 \%$ increase in a low abundance, yet, functionally critical (Raghu et al., 2009b) (see Discussion) species of PA, PA 34:2, of the 11 molecular species of PA analyzed. Although PA 34:2 is not affected by the Pld2 genotype in the absence of the transgene, it no longer accumulates in the SwAPP forebrain upon ablation of PLD2, suggesting it may be a bona fide product of PLD2 upon SwAPP overexpression.

\section{Reduction in PLD2 levels does not alter APP or A $\beta$ levels in SwAPP mice}

An important question is whether the rescue of the learning performance reflects a reduction in amyloidogenesis. Thus a biochemical analysis of the brains from 12-month-old SwAPP/Pld2 mice was conducted after the RAWM test. Western blot analysis showed that full-length APP levels are not affected by ablation of one or two copies of Pld2 (Fig. 8 A,B). Importantly, no significant differences were found in the levels of soluble and insoluble hu-
B

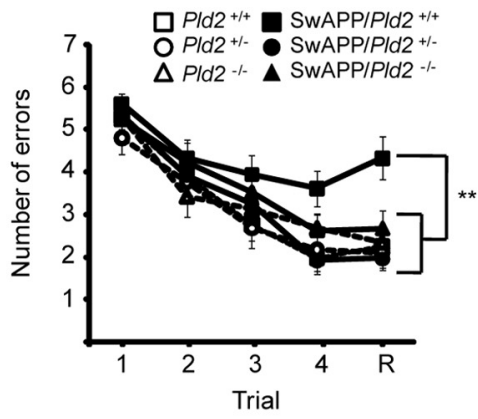

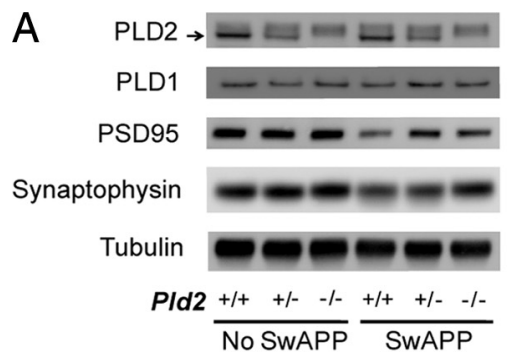

B
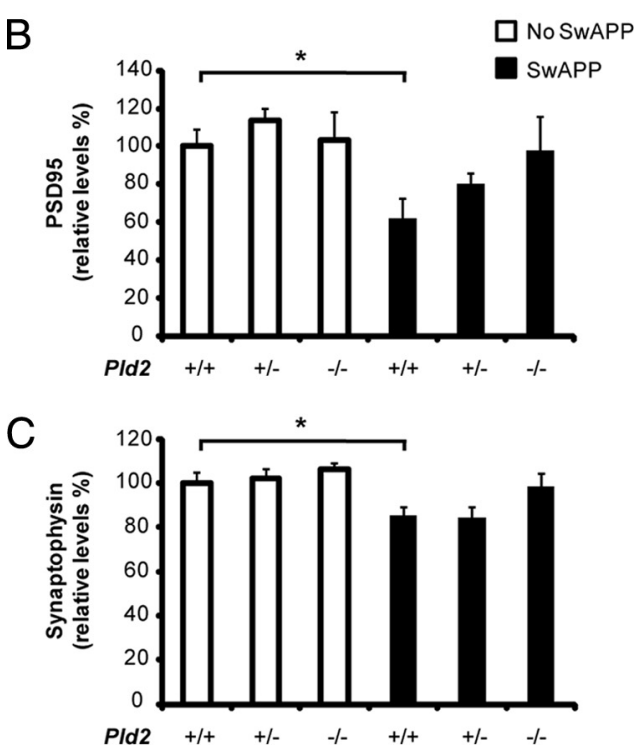

Figure 6. PLD2 ablation confers synaptic protection in the forebrain of SwAPP mice. After RAWM testing, forebrains from 12-month-old PId2/SwAPP mice were processed for biochemical analysis. $\boldsymbol{A}$, Protein levels were evaluated by Western blot analysis of PLD2, PLD1, PSD95, synaptophysin, and tubulin (representative blots are shown). $\boldsymbol{B}$, Quantification of PSD95 levels by densitometric analysis. C, Quantification of synaptophysin levels by densitometric analysis. Values denote means \pm SEM. $n=4,{ }^{*} p<0.05$.

man $\mathrm{A} \beta_{1-40}$ and $\mathrm{A} \beta_{1-42}$ (Fig. $8 C, D$ ) and total murine $\mathrm{A} \beta_{1-40}$ and $\mathrm{A} \beta_{1-42}$ (supplemental Fig. 4, available at www.jneurosci.org as supplemental material) upon disruption of Pld2 gene, as measured by ELISA. Overall, ablation of PLD2 protected from the memory deficits in the SwAPP mice, and this protection was 


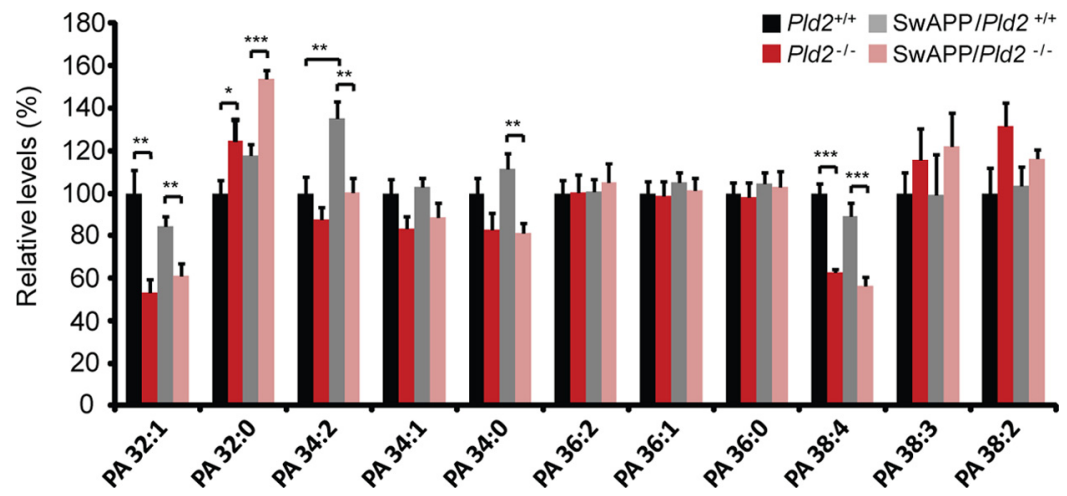

Figure 7. Effect of SwAPP overexpression and PId 2 genotypes on PA levels. After RAWM testing, forebrains from 12-month-old PId2/SwAPP mice were processed for lipid biochemical analysis. Forebrain lipids were extracted from PId $2^{+/+}$and $P I d 2^{-1-}$ mice with and without SwAPP transgene and subjected to LC-MS analysis. Relative amounts of PA species were measured in mutant mice compared with control mice (PId2 ${ }^{+/+}$, no SwAPP). Values denote mean \pm SEM $(n=6-8) .{ }^{*} p<0.05,{ }^{* *} p<0.01$, ${ }^{* * *} p<0.001$. The nomenclature for fatty acid composition of phospholipids is denoted as total chain length/number of unsaturated bonds. Absolute amounts of the various molecular species of PA are presented in supplemental Table 2, available at www.jneurosci.org as supplemental material.

A
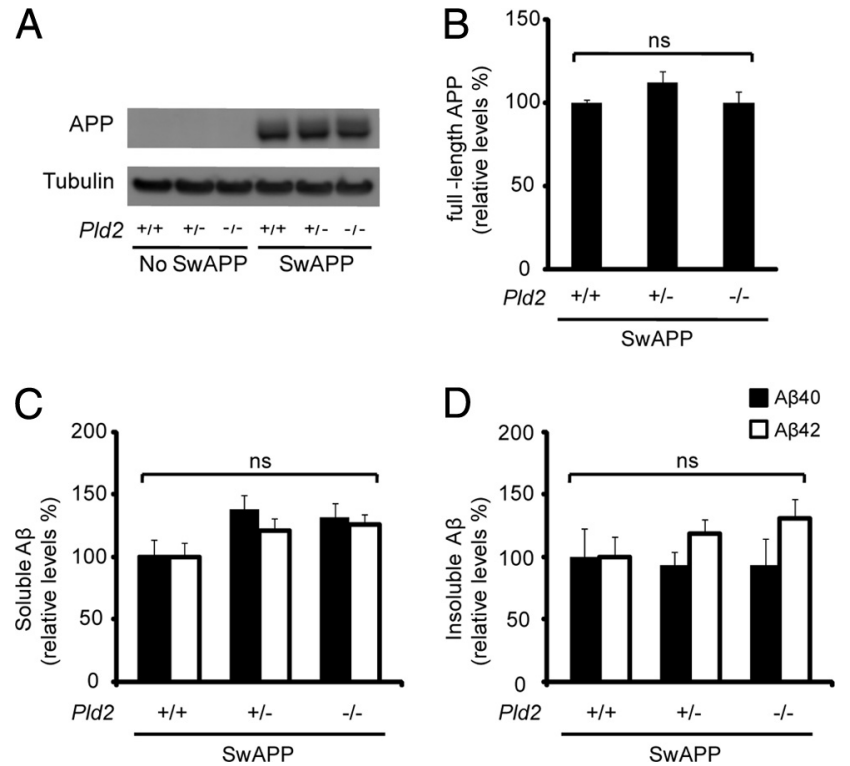

Figure 8. Effect of SwAPP overexpression and PId2 genotypes on APP processing. $A-D$, After RAWM testing, forebrains from 12-month-old PId2/SwAPP mice were processed for biochemical analysis. $\boldsymbol{A}$, Protein levels were evaluated by Western blot analysis of APP and tubulin (representative blots are shown). B, Quantification of full-length human APP levels was done by densitometric analysis. Values denote means \pm SEM $(n=6)$. C, D, ELISA analysis of the levels of soluble $A \beta 40$ and $A \beta 42(\boldsymbol{C})$, and insoluble $A \beta 40$ and $A \beta 42(\boldsymbol{D})$. Values denote means \pm SEM; PId $2^{+/+} / \operatorname{SWAPP}(n=6) ; \operatorname{PId} 2^{+/-} / \operatorname{SWAPP}(n=8) ; \operatorname{PId} 2^{-/-} / \operatorname{SWAPP}(n=7)$.

concomitant with a high $\mathrm{A} \beta$ burden further suggesting that PLD2 acts downstream of $\mathrm{A} \beta$ signaling in this $\mathrm{AD}$ model.

\section{Discussion}

Previous studies have implicated PLD in AD pathogenesis either as a mediator of APP trafficking, presenilin regulation or downstream target of A $\beta$ (Kanfer et al., 1986, 1996, 1998; Singh et al., 1997a,b, 1998; Cai et al., 2006a,b; Jin et al., 2007; Brandenburg et al., 2008; Liu et al., 2009; Oliveira and Di Paolo, 2010). Importantly, an increase in total PLD activity was reported in AD brain homogenates, using an in vitro enzymatic assay (Kanfer et al., 1996). However, these studies have established neither the pathophysiological relevance of the PLD pathway in $\mathrm{AD}$ in vivo models nor the precise role of PLD2 in AD pathogenesis. For instance, cell culture studies have established a role for PLD1, but not PLD2, in the trafficking of both APP and PS1 with important implications for APP metabolism and $\mathrm{A} \beta$ secretion (Cai et al., 2006a,b; Liu et al., 2009; Oliveira and Di Paolo, 2010). Our study suggests that PLD2, unlike PLD1, may be a downstream target of $\mathrm{A} \beta$ oligomers.

Although the synaptotoxic actions of $\mathrm{A} \beta$ oligomers are beginning to be understood, the underlying molecular mechanisms are still unclear. This study provides experimental and genetic evidence demonstrating that PLD, and PLD2 in particular, is pathophysiologically relevant in the context of mouse models of $\mathrm{AD}$ and in the synaptotoxic actions of A $\beta 42$ oligomers. Specifically, PLD2 ablation confers protection against the synapseimpairing actions of $\mathrm{A} \beta 42$ in an ex vivo model of synaptic plasticity (Fig. 3) and against the cognitive deficits and synapse impairment induced by overexpression of SwAPP (Figs. 5, 6). This protective effect occurs despite high $\mathrm{A} \beta$ levels (Fig. 8), as observed previously in various other AD mouse models (Roberson et al., 2007; Sanchez-Mejia et al., 2008; Dziewczapolski et al., 2009; Gimbel et al., 2010). Thus, our data are consistent with scenarios whereby PLD2 and its enzymatic product (1) mediate key signaling cascades downstream of $A \beta$; (2) regulate the (cell surface) availability of putative $A \beta$ receptors at synapses; or (3) alter the capacity of $A \beta$ to bind to its putative receptors. Because a pool of PLD isozymes is associated with lipid rafts and that $\mathrm{A} \beta$ has a high affinity for these lipid microdomains (Yanagisawa, 2007; Ariga et al., 2008; Hebbar et al., 2008), a tantalizing hypothesis is that PLD2 ablation may disrupt the raft-dependent signaling of $A \beta$. Importantly, ablation of one or two copies of PLD2 not only reduces basal PLD activity, but it also blocks oA $\beta 42$-induced increase in this activity. Therefore, the protective effect may reflect either changes in PLD activity or a combination of both. Finally, although our data suggest that neurons expressing reduced amounts of PLD2 may play a central role in this protective effect, a contribution of other cell types, such as glial cells, cannot be ruled out.

Importantly, our results expand on previous studies showing that impairment of signaling lipids plays a key role in $\mathrm{AD}$ pathogenesis in animal models. Specifically, $A \beta$ oligomers have been shown to dysregulate the PLC and PLA2 pathways with major implications for the signaling downstream of $\mathrm{PI}(4,5) \mathrm{P}_{2}$ and arachidonic acid in the brain (Singh et al., 1995; Berman et al., 2008; Sanchez-Mejia et al., 2008). This study provides further support to the hypothesis that phospholipase signaling may be globally altered in $\mathrm{AD}$ and that $\mathrm{A} \beta$-induced $\mathrm{Ca}^{2+}$-dyshomeostasis through glutamate receptors or other mechanisms may be underlying these changes. Indeed, we find that oligomeric $\mathrm{A} \beta$ affects the localization of PLD2 in a manner dependent upon extracellular $\mathrm{Ca}^{2+}$, thus suggesting a role for $\mathrm{Ca}^{2+}$ entry in the activation of three phospholipase families, PLC, PLA2 and PLD2. Here, we show that pharmacological inhibition of PLC does not prevent A $\beta$-induced PLD2 relocalization, suggesting that PLD2 either lies upstream or acts independently of PLC in the $\mathrm{A} \beta$ signaling pathway (Fig. $1 D$ ). Moreover, we show that PLD2 relocalization induced by 
oA $\beta 42$ is blocked by inhibition of cPLA2 (Fig. $1 D$ ), in agreement with other studies showing that PLD2 activation occurs downstream of $\mathrm{Ca}^{2+}$ entry and cPLA2 stimulation in a lymphocytic leukemia cell line (Kim et al., 1999). More careful molecular genetic/genetic approaches should provide a definitive answer concerning the crosstalk between these enzymes and their precise role in this cytotoxic signaling pathway.

To understand the impact on PLD activity and PA metabolism of Pld2 ablation, SwAPP overexpression as well as the interaction between these two genetic manipulations, we have used LC-MS. The in vivo PLD activity assay relies on the measurement of PEtOH, which is the product of PLD catalysis in the presence of ethanol. In contrast to PA, PEtOH is a specific product of PLD and is very stable, due to its poor consumption by lipases (Gustavsson, 1995). Importantly, changes in specific molecular species of $\mathrm{PEtOH}$ can be correlated with those in the corresponding species of PA, thus providing clues on the contribution of PLD to the synthesis of specific pools of PA. Results from our analysis suggest that a dysregulation of PLD function and PA metabolism may be associated with $\mathrm{AD}$ pathogenesis and that specific pools of PA may be affected. Indeed, while brains from SwAPP mice showed an overall increase in PEtOH levels and thus total PLD activity (Fig. 4A), a more detailed analysis of PEtOH species showed that only a subset of species, such as PEtOH 32:1, 34:2, 34:1 and 34:1, were increased in mutant brain (Fig. 4B; supplemental Table 1, available at www.jneurosci.org as supplemental material). A direct comparison of these $\mathrm{PEtOH}$ species with the corresponding molecular species of PA (Fig. 7) revealed a remarkable and specific increase in both PEtOH 34:2 and PA 34:2 in the brain of SwAPP mice, and since the latter increase was rescued by PLD2 ablation, we speculate that this PA species may be a bona fide product of a hyperactivated PLD2 in the SwAPP brain. Interestingly, PA 34:2 is the only molecular species of PA that was found to accumulate in Drosophila melanogaster photoreceptors upon overexpression of PLD of the 17 species of PA measured (Raghu et al., 2009b). Consistent with a pathogenic role of this lipid, overexpression of the fly ortholog of PLD in the photoreceptors results in the degeneration of photoreceptors. Collectively, these data suggest that increased PLD levels/activity and the resulting accumulation of PA 34:2 may be detrimental to cell physiology, at least in some cell types. In contrast to $\mathrm{PEtOH}$ 34:2, other molecular species of PEtOH (i.e., 36:2, 36:1, 36:0, 38:3, 38:2 and 38:1) were not affected by SwAPP overexpression (Fig. $4 B$ ) and the corresponding PA species were equally insensitive to the presence of the transgene (Fig. 7). Altogether, this combined in vivo analysis of $\mathrm{PEtOH}$ and PA species has allowed for the implication of specific PLD products in $\mathrm{AD}$. However, future studies will be required to determine whether these lipid products are simple AD biomarkers or key contributors to AD pathogenesis.

In addition, our LC-MS analysis uncovered interesting changes as well as some plasticity in the metabolism of PA as a result of PLD2 manipulation. For instance, of the two molecular species that were significantly decreased in the $P l d 2^{-1-}$ forebrains (in the absence of SwAPP transgene), PA 32:1 and 38:4, only the former is believed to be a direct product of PLD (Hodgkin et al., 1998; Pettitt et al., 2001). Indeed, the primary source of PA 38:4 is thought to originate from DAG kinase in the PLC pathway (Hodgkin et al., 1998). However, ethanol injections led to the production of PEtOH 38:4 in mouse brain (Fig. $4 B$; supplemental Table 1, available at www.jneurosci.org as supplemental material), suggesting that the corresponding molecular species of PC can be a bona fide substrate for PLD in vivo. On the other hand, hints that compensatory changes in the metabolism of PA can occur as a result of PLD2 ablation are suggested by the fact that knocking out PLD2 causes a modest, but significant increase in brain PA 32:0, a phenomenon exacerbated by SwAPP overexpression (Fig. 7; supplemental Table 2, available at www. jneurosci.org as supplemental material). Considering the complexity of PA metabolism, adaptive changes can indeed be expected, perhaps allowing PLD2-deficient cells, tissues and organisms to cope with the deficiency of specific pools of PA that are normally produced by PLD2. Such compensatory mechanisms in the metabolism of PA may not be as efficient when PLD is either overexpressed (Raghu et al., 2009a,b) or hyperactivated upon stress conditions, such as during $\mathrm{A} \beta$ elevation (this study). We speculate that PLD2 ablation, which results in a $40 \%$ decrease in brain-associated total PLD activity (supplemental Fig. $1 C$, available at www.jneurosci.org as supplemental material), may confer protection during $\mathrm{A} \beta$ elevation by correcting some of the aberrant features of PA metabolism occurring in this condition.

Finally, our study expands on previous work showing that blocking the action of $A \beta$ may be beneficial for the treatment of AD (Gong et al., 2006; Trinchese et al., 2008). Collectively, results presented in this study identify PLD2 as a new player in AD pathogenesis and, together with the lack of obvious detrimental phenotypes in $P l d 2^{-1-}$ mice, suggest that PLD2 inhibitors may be valuable therapeutic agents. Similarly, PLD1 inhibitors may be useful for specific therapeutic avenues, as our recent mouse genetic study has implicated this other isoform in the modulation of autophagy (Dall'Armi et al., 2010), a cellular degradative pathway involved in a growing number or human disorders, including $\mathrm{AD}$.

\section{References}

Almeida CG, Tampellini D, Takahashi RH, Greengard P, Lin MT, Snyder EM, Gouras GK (2005) Beta-amyloid accumulation in APP mutant neurons reduces PSD-95 and GluR1 in synapses. Neurobiol Dis 20:187-198.

Ariga T, McDonald MP, Yu RK (2008) Role of ganglioside metabolism in the pathogenesis of Alzheimer's disease-a review. J Lipid Res 49:1157-1175.

Bader MF, Vitale N (2009) Phospholipase D in calcium-regulated exocytosis: lessons from chromaffin cells. Biochim Biophys Acta 1791:936-941.

Berman DE, Dall'Armi C, Voronov SV, McIntire LB, Zhang H, Moore AZ, Staniszewski A, Arancio O, Kim TW, Di Paolo G (2008) Oligomeric amyloid-beta peptide disrupts phosphatidylinositol-4,5-bisphosphate metabolism. Nat Neurosci 11:547-554.

Brandenburg LO, Konrad M, Wruck C, Koch T, Pufe T, Lucius R (2008) Involvement of formyl-peptide-receptor-like- 1 and phospholipase $\mathrm{D}$ in the internalization and signal transduction of amyloid beta 1-42 in glial cells. Neuroscience 156:266-276.

Burns M, Gaynor K, Olm V, Mercken M, LaFrancois J, Wang L, Mathews PM, Noble W, Matsuoka Y, Duff K (2003) Presenilin redistribution associated with aberrant cholesterol transport enhances beta-amyloid production in vivo. J Neurosci 23:5645-5649.

Cai D, Zhong M, Wang R, Netzer WJ, Shields D, Zheng H, Sisodia SS, Foster DA, Gorelick FS, Xu H, Greengard P (2006a) Phospholipase D1 corrects impaired betaAPP trafficking and neurite outgrowth in familial Alzheimer's disease-linked presenilin-1 mutant neurons. Proc Natl Acad Sci U S A 103:1936-1940.

Cai D, Netzer WJ, Zhong M, Lin Y, Du G, Frohman M, Foster DA, Sisodia SS, Xu H, Gorelick FS, Greengard P (2006b) Presenilin-1 uses phospholipase D1 as a negative regulator of beta-amyloid formation. Proc Natl Acad Sci U S A 103:1941-1946.

Chan R, Uchil PD, Jin J, Shui G, Ott DE, Mothes W, Wenk MR (2008) Retroviruses human immunodeficiency virus and murine leukemia virus are enriched in phosphoinositides. J Virol 82:11228-11238.

Dahlgren KN, Manelli AM, Stine WB Jr, Baker LK, Krafft GA, LaDu MJ (2002) Oligomeric and fibrillar species of amyloid-beta peptides differentially affect neuronal viability. J Biol Chem 277:32046-32053. 
Dall'Armi C, Hurtado-Lorenzo A, Tian H, Morel E, Nezu A, Chan RB, Yu WH, Robinson KS, Yeku O, Small SA, Duff K, Frohman MA, Wenk MR, Yamamoto A, Di Paolo G (2010) The phospholipase D1 pathway modulates macroautophagy. Nat Commun, in press.

Demuro A, Mina E, Kayed R, Milton SC, Parker I, Glabe CG (2005) Calcium dysregulation and membrane disruption as a ubiquitous neurotoxic mechanism of soluble amyloid oligomers. J Biol Chem 280:17294-17300.

De Strooper B, Vassar R, Golde T (2010) The secretases: enzymes with therapeutic potential in Alzheimer disease. Nat Rev Neurol 6:99-107.

Donaldson JG (2009) Phospholipase D in endocytosis and endosomal recycling pathways. Biochim Biophys Acta 1791:845-849.

Du G, Altshuller YM, Vitale N, Huang P, Chasserot-Golaz S, Morris AJ, Bader MF, Frohman MA (2003) Regulation of phospholipase D1 subcellular cycling through coordination of multiple membrane association motifs. J Cell Biol 162:305-315.

Du G, Huang P, Liang BT, Frohman MA (2004) Phospholipase D2 localizes to the plasma membrane and regulates angiotensin II receptor endocytosis. Mol Biol Cell 15:1024-1030.

Dziewczapolski G, Glogowski CM, Masliah E, Heinemann SF (2009) Deletion of the alpha 7 nicotinic acetylcholine receptor gene improves cognitive deficits and synaptic pathology in a mouse model of Alzheimer's disease. J Neurosci 29:8805-8815.

Fei W, Shui G, Gaeta B, Du X, Kuerschner L, Li P, Brown AJ, Wenk MR, Parton RG, Yang H (2008) Fld1p, a functional homologue of human seipin, regulates the size of lipid droplets in yeast. J Cell Biol 180:473-482.

Freyberg Z, Siddhanta A, Shields D (2003) "Slip, sliding away": phospholipase D and the Golgi apparatus. Trends Cell Biol 13:540-546.

Gimbel DA, Nygaard HB, Coffey EE, Gunther EC, Laurén J, Gimbel ZA, Strittmatter SM (2010) Memory impairment in transgenic Alzheimer mice requires cellular prion protein. J Neurosci 30:6367-6374.

Gong B, Cao Z, Zheng P, Vitolo OV, Liu S, Staniszewski A, Moolman D, Zhang H, Shelanski M, Arancio O (2006) Ubiquitin hydrolase Uch-L1 rescues beta-amyloid-induced decreases in synaptic function and contextual memory. Cell 126:775-788.

Green KN, LaFerla FM (2008) Linking calcium to Abeta and Alzheimer's disease. Neuron 59:190-194.

Gustavsson L (1995) ESBRA 1994 Award Lecture. Phosphatidylethanol formation: specific effects of ethanol mediated via phospholipase D. Alcohol Alcohol 30:391-406.

Haass C, Selkoe DJ (2007) Soluble protein oligomers in neurodegeneration: lessons from the Alzheimer's amyloid beta-peptide. Nat Rev Mol Cell Biol 8:101-112.

Hartmann T, Kuchenbecker J, Grimm MO (2007) Alzheimer's disease: the lipid connection. J Neurochem 103 [Suppl 1]:159-170.

Haucke V, Di Paolo G (2007) Lipids and lipid modifications in the regulation of membrane. Curr Opin Cell Biol 19:426-435.

Hebbar S, Lee E, Manna M, Steinert S, Kumar GS, Wenk M, Wohland T, Kraut R (2008) A fluorescent sphingolipid binding domain peptide probe interacts with sphingolipids and cholesterol-dependent raft domains. J Lipid Res 49:1077-1089.

Hodgkin MN, Pettitt TR, Martin A, Michell RH, Pemberton AJ, Wakelam MJ (1998) Diacylglycerols and phosphatidates: which molecular species are intracellular messengers? Trends Biochem Sci 23:200-204.

Hsiao K, Chapman P, Nilsen S, Eckman C, Harigaya Y, Younkin S, Yang F, Cole G (1996) Correlative memory deficits, Abeta elevation, and amyloid plaques in transgenic mice. Science 274:99-102.

Hsieh H, Boehm J, Sato C, Iwatsubo T, Tomita T, Sisodia S, Malinow R (2006) AMPAR removal underlies Abeta-induced synaptic depression and dendritic spine loss. Neuron 52:831-843.

Jenkins GM, Frohman MA (2005) Phospholipase D: a lipid centric review. Cell Mol Life Sci 62:2305-2316.

Jin JK, Ahn BH, Na YJ, Kim JI, Kim YS, Choi EK, Ko YG, Chung KC, Kozlowski PB, Min DS (2007) Phospholipase D1 is associated with amyloid precursor protein in Alzheimer's disease. Neurobiol Aging 28:1015-1027.

Kanfer JN, Hattori H, Orihel D (1986) Reduced phospholipase D activity in brain tissue samples from Alzheimer's disease patients. Ann Neurol 20:265-267.

Kanfer JN, Singh IN, Pettegrew JW, McCartney DG, Sorrentino G (1996) Phospholipid metabolism in Alzheimer's disease and in a human cholinergic cell. J Lipid Mediat Cell Signal 14:361-363.

Kanfer JN, Sorrentino G, Sitar DS (1998) Phospholipases as mediators of amyloid beta peptide neurotoxicity: an early event contributing to neu- rodegeneration characteristic of Alzheimer's disease. Neurosci Lett 257:93-96.

Kim JH, Lee BD, Kim Y, Lee SD, Suh PG, Ryu SH (1999) Cytosolic phospholipase A2-mediated regulation of phospholipase D2 in leukocyte cell lines. J Immunol 163:5462-5470.

Kriem B, Sponne I, Fifre A, Malaplate-Armand C, Lozac'h-Pillot K, Koziel V, Yen-Potin FT, Bihain B, Oster T, Olivier JL, Pillot T (2005) Cytosolic phospholipase A2 mediates neuronal apoptosis induced by soluble oligomers of the amyloid-beta peptide. FASEB J 19:85-87.

Lambert MP, Barlow AK, Chromy BA, Edwards C, Freed R, Liosatos M, Morgan TE, Rozovsky I, Trommer B, Viola KL, Wals P, Zhang C, Finch CE, Krafft GA, Klein WL (1998) Diffusible, nonfibrillar ligands derived from Abeta1-42 are potent central nervous system neurotoxins. Proc Natl Acad Sci U S A 95:6448-6453.

Laulagnier K, Grand D, Dujardin A, Hamdi S, Vincent-Schneider H, Lankar D, Salles JP, Bonnerot C, Perret B, Record M (2004) PLD2 is enriched on exosomes and its activity is correlated to the release of exosomes. FEBS Lett 572:11-14.

Laurén J, Gimbel DA, Nygaard HB, Gilbert JW, Strittmatter SM (2009) Cellular prion protein mediates impairment of synaptic plasticity by amyloid-beta oligomers. Nature 457:1128-1132.

LeDoux JE (2000) Emotion circuits in the brain. Annu Rev Neurosci 23:155-184.

Liu Y, Zhang YW, Wang X, Zhang H, You X, Liao FF, Xu H (2009) Intracellular trafficking of presenilin 1 is regulated by beta-amyloid precursor protein and phospholipase D1. J Biol Chem 284:12145-12152.

Morris AJ, Frohman MA, Engebrecht J (1997) Measurement of phospholipase D activity. Anal Biochem 252:1-9.

Oliveira TG, Di Paolo G (2010) Phospholipase D in brain function and Alzheimer's disease. Biochim Biophys Acta 1801:799-805.

Paylor R, Tracy R, Wehner J, Rudy JW (1994) DBA/2 and C57BL/6 mice differ in contextual fear but not auditory fear conditioning. Behav Neurosci 108:810-817.

Pettitt TR, McDermott M, Saqib KM, Shimwell N, Wakelam MJ (2001) Phospholipase D1b and D2a generate structurally identical phosphatidic acid species in mammalian cells. Biochem J 360:707-715.

Puzzo D, Vitolo O, Trinchese F, Jacob JP, Palmeri A, Arancio O (2005) Amyloid-beta peptide inhibits activation of the nitric oxide/cGMP/ cAMP-responsive element-binding protein pathway during hippocampal synaptic plasticity. J Neurosci 25:6887-6897.

Raghu P, Manifava M, Coadwell J, Ktistakis NT (2009a) Emerging findings from studies of phospholipase D in model organisms (and a short update on phosphatidic acid effectors). Biochim Biophys Acta 1791:889-897.

Raghu P, Coessens E, Manifava M, Georgiev P, Pettitt T, Wood E, GarciaMurillas I, Okkenhaug H, Trivedi D, Zhang Q, Razzaq A, Zaid O, Wakelam M, O'Kane CJ, Ktistakis N (2009b) Rhabdomere biogenesis in Drosophila photoreceptors is acutely sensitive to phosphatidic acid levels. J Cell Biol 185:129-145.

Roberson ED, Scearce-Levie K, Palop JJ, Yan F, Cheng IH, Wu T, Gerstein H, Yu GQ, Mucke L (2007) Reducing endogenous tau ameliorates amyloid beta-induced deficits in an Alzheimer's disease mouse model. Science 316:750-754.

Roth MG (2008) Molecular mechanisms of PLD function in membrane traffic. Traffic 9:1233-1239.

Sanchez-Mejia RO, Newman JW, Toh S, Yu GQ, Zhou Y, Halabisky B, Cissé M, Scearce-Levie K, Cheng IH, Gan L, Palop JJ, Bonventre JV, Mucke L (2008) Phospholipase A2 reduction ameliorates cognitive deficits in a mouse model of Alzheimer's disease. Nat Neurosci 11:1311-1318.

Schmidt SD, Nixon RA, Mathews PM (2005) ELISA method for measurement of amyloid-beta levels. Methods Mol Biol 299:279-297.

Shankar GM, Bloodgood BL, Townsend M, Walsh DM, Selkoe DJ, Sabatini BL (2007) Natural oligomers of the Alzheimer amyloid-beta protein induce reversible synapse loss by modulating an NMDA-type glutamate receptor-dependent signaling pathway. J Neurosci 27:28662875.

Singh IN, McCartney DG, Kanfer JN (1995) Amyloid-beta protein (25-35) stimulation of phospholipases A, C and D activities of La-N-2 cells. FEBS Lett 365:125-128.

Singh IN, Sorrentino G, Sitar DS, Kanfer JN (1997a) Indomethacin and nordihydroguaiaretic acid inhibition of amyloid beta protein (25-35) ac- 
tivation of phospholipases A(2) and D of LA-N-2 cells. Neurosci Lett 222:5-8.

Singh IN, Sato K, Takashima A, Kanfer JN (1997b) Activation of LA-N-2 cell phospholipases by single alanine substitution analogs of amyloid beta peptide (25-35). FEBS Lett 405:65-67.

Singh IN, Sorrentino G, Kanfer JN (1998) Activation of LA-N-2 cell phospholipase D by amyloid beta protein (25-35). Neurochem Res 23:1225-1232.

Small SA, Gandy S (2006) Sorting through the cell biology of Alzheimer's disease: intracellular pathways to pathogenesis. Neuron 52:15-31.

Snyder EM, Nong Y, Almeida CG, Paul S, Moran T, Choi EY, Nairn AC, Salter MW, Lombroso PJ, Gouras GK, Greengard P (2005) Regulation of NMDA receptor trafficking by amyloid-beta. Nat Neurosci 8:1051-1058.

Stace CL, Ktistakis NT (2006) Phosphatidic acid- and phosphatidylserinebinding proteins. Biochim Biophys Acta 1761:913-926.

Trinchese F, Fa' M, Liu S, Zhang H, Hidalgo A, Schmidt SD, Yamaguchi H,
Yoshii N, Mathews PM, Nixon RA, Arancio O (2008) Inhibition of calpains improves memory and synaptic transmission in a mouse model of Alzheimer disease. J Clin Invest 118:2796-2807.

Vassar R, Kovacs DM, Yan R, Wong PC (2009) The beta-secretase enzyme BACE in health and Alzheimer's disease: regulation, cell biology, function, and therapeutic potential. J Neurosci 29:12787-12794.

Vitolo OV, Sant'Angelo A, Costanzo V, Battaglia F, Arancio O, Shelanski M (2002) Amyloid beta-peptide inhibition of the PKA/CREB pathway and long-term potentiation: reversibility by drugs that enhance cAMP signaling. Proc Natl Acad Sci U S A 99:13217-13221.

Walsh DM, Klyubin I, Fadeeva JV, Cullen WK, Anwyl R, Wolfe MS, Rowan MJ, Selkoe DJ (2002) Naturally secreted oligomers of amyloid beta protein potently inhibit hippocampal long-term potentiation in vivo. Nature 416:535-539.

Yanagisawa K (2007) Role of gangliosides in Alzheimer's disease. Biochim Biophys Acta 1768:1943-1951. 